\title{
ОСОБЕННОСТИ РЕГУЛИРОВАНИЯ ПРИОРИТЕТНЫХ ОБЛАСТЕЙ ЦИФРОВОЙ ЭКОНОМИКИ
}

\author{
(c) 2020 Бекбергенева Дина Евгеньевна \\ кандидат экономических наук, доцент, кафедра теории практики и управления \\ Оренбургский филиал РАНХиГС, Россия, Оренбург \\ E-mail: dinabekber@mail.ru
}

В статье представлены результаты исследования приоритетных сфер цифровой экономики, требующих особого регулирования: защита прав потребителей, защита данных, кибербезопасность и электронная торговля. Отмечается, что в настоящее время отсутствует консенсус в отношении содержания норм и стандартов, которые могли бы направлять и регулировать современные изменения в цифровой экономике. Особое внимание уделено важности понимания и учета региональными бизнес-сообществами специфики развития сложных цифровых систем на международном, региональном, национальном и иногда субнациональном уровнях.

Ключевые слова: циифровая экономика, права потребителей, защита данных, кибербезопасность, электронная торговля

\section{Введение}

Развивающаяся цифровая экономика, которая включает в себя широкий спектр цифровых услуг и электронную торговлю (e-commerce) становится важным двигателем экономического развития регионов, открывая новые рыночные каналы для местного бизнеса, содействуя внутренней и внешней торговле, расширяя доступ к разнообразным услугам, что повышает налоговые поступления в бюджет региона и страны. По мере распространения цифровых инноваций по всему миру местные деловые круги продолжают сталкиваться с препятствиями на пути преодоления технологического и цифрового разрыва. Национальная политика, законы и нормативные акты, регулирующие это новое пространство, могут оказывать значительное влияние на развитие цифровых инструментов. При этом органы государственной власти должны обеспечить благоприятные политические и правовые условия, способствующие активному росту интернет-активности коммерческих предприятий и организаций.

Мировая экономика неуклонно продолжает переходить в цифровую сферу, в то время как правила и нормы, обеспечивающие цифровую экономику, во многих странах все еще находятся на стадии зарождения, зачастую препятствуя как росту национального дохода, так и доступу на мировые рынки. В то же время технологические инновации и киберугрозы опережают развитие национальных стратегий и все больше требуют новых подходов и более широкого международного сотрудничества. Поскольку экономическая деятельность все чаще происходит в режиме онлайн, местные бизнес-сообщества должны иметь право голоса в разработке правил и положений электронной торговли, чтобы обеспечить устойчивость их реализации в режиме онлайн и оффлайн. Слишком часто структуры, регулирующие цифровую экономику, управляются государством при минимальном участии заинтересованных сторон, таких как представители малого и среднего бизнеса, чьи голоса имеют значение для экономического развития региона.

\section{Цели и методы исследования}

Для формирования полной и единой системы мнений и положений о правилах регулирования цифровой экономики в регионах представителям предпринимателей - профессиональным ассоциациям или торгово-промышленным палатам - требуется информация о потребностях и целях делового сообщества, так как они могут существенно отличаться в зависимости от того, предоставляет ли компания товары или услуги онлайн или нет. Необходимая информация может быть собрана несколькими способами, включая: опросы, фокус-группы и экспертные оценки членов профессиональных ассоциаций. При этом необходимо собрать информацию о проблемах в цифровом пространстве, существующих у всех участников местного бизнеса, а не только у крупных или технологически успешных 
компаний, и определить возможные решения. Формирование консенсуса по политическим позициям может быть сложной задачей, поскольку у бизнесменов могут быть различные интересы в цифровой экономике. Главное - сбалансировать конкурирующие требования и расставить приоритеты в достижении общих целей.

\section{Результаты исследования}

Природа цифровой экономики порождает уникальные вопросы о том, как ее регулировать. Традиционные подходы к защите потребителей, соблюдению контрактов и хранению информации должны быть пересмотрены для цифровой сферы. Кроме того, законы, нормативные акты и политика, регулирующие цифровую экономику, должны согласовываться с усилиями по улучшению операционной среды, включая ИТ-инфраструктуру, интернет-услуги, цифровые платформы, экосистемы и устройства.

Выделим четыре приоритетные области цифровой экономики, требующие пристального внимания по вопросам регулирования на региональном рынке:

- защита прав потребителей;

- защита данных;

- кибербезопасность;

- электронные транзакции.

Как по отдельности, так и совместно эти аспекты цифровой экономики могут выступать в качестве мультипликаторов силы, как для развития деловых возможностей, так и для защиты государственных интересов. Представим особенности функционирования данных приоритетных областей цифровой экономики в настоящее время в регионах:

1) Защита прав потребителей является важной областью правового обеспечения цифрового развития, поскольку охраняет физических и юридических лиц, приобретающих товары и услуги с помощью электронных и неэлектронных средств. Закон «О защите прав потребителей» направлен на защиту потребителей от «неправильно представленных, поврежденных, неисправных и опасных товаров и услуг, а также от недобросовестной торговой и кредитной практики» [1]. Защита прав потребителей в электронной торговле имеет особое значение для создания надежной среды в сети Интернете. Наличие сильного режима защиты прав потребителей также пойдет на пользу местному бизнес-сообществу - например, в рамках сделок «бизнес-бизнес» (В2В) - за счет повышения доверия к электронной торговле, упрощения цифровых транзакций и расширения клиентской базы [4].

В настоящее время традиционные решения в области защиты прав потребителей зачастую не предназначены для решения новых проблем, таких как, например, регулирование рекламы в социальных сетях. В результате государство не имеет надлежащих механизмов защиты участников интернет-сообщества.

Считаем, что особое внимание необходимо уделить трем основным стадиям потребительских сделок:

- фазе предварительной покупки (обязанности по раскрытию информации и добросовестной рекламе);

- фазе оплаты (условия сделок, прозрачная/ безопасная оплата и защита данных);

- фазе поставки/послепродажного обслуживания (разрешение споров и возмещение ущерба и право на отзыв/отмену сделки).

Важной частью защиты прав потребителей является разрешение споров, которые часто возникают в электронных сделках на этапе послепродажного обслуживания потребителей [5].

2) Цифровая экономика способствует созданию и распространению беспрецедентного количества данных. Правила защиты данных должны распространяться как на физических лиц, приобретающих товары и услуги в электронном виде, так и на компании, которые покупают, продают или предоставляют услуги в режиме онлайн. Защита данных служит целям конфиденциальности и безопасности и традиционно стоит в центре внимания национальных нормативных актов, отчасти из-за особого внимания правительства в области национальной безопасности. Защита данных стала координационным центром для бизнес-сообщества, регулирующих органов и потребителей. Все данные следуют этапам жизненного цикла товара: сбор и обработка данных, хранение, передача и утилизация, которые лежат в основе большинства нормативных подходов во всем мире. Потребители также обеспокоены тем, как будут собираться и использоваться их личные данные, особенно в таких чувствительных областях, как биометрические данные. Как и в случае с защитой прав потребителей, не существует международных признанных стандартов, которыми можно было бы руководствоваться при разработке национальных правил защиты данных. 
Это не только влияет на бизнес-сообщество, которое иногда должно разрабатывать отдельные процедуры защиты данных, но и оказывает существенное влияние на способность регулятора обеспечивать соблюдение закона «О персональных данных» [3].

3) Регулирование кибербезопасности, которая защищает информационные технологии и компьютерные системы от хакерских атак, является глобальной проблемой, которая актуальна для всех членов бизнес-сообщества и всех, кто занимается онлайн-деятельностью. В последние годы атаки на компьютеры и информационные сети, как государственные, так и частные, стали более масштабными и серьезными, нанося ущерб государственным учреждениям, предприятиям и физическим лицам. Кибербезопасность включает активы как государственных, так и частных субъектов и охватывает «подключенные вычислительные устройства, персонал, инфраструктуру, приложения, услуги, телекоммуникационные системы и совокупность передаваемой и/или хранимой информации» [2].

Законодательство о киберпреступности, которое криминализирует целый ряд цифровых преступлений, таких как взлом и кража личных данных, является наиболее распространенным подходом и может быть эффективным, если оно сопровождается соответствующими санкциями и строгим принуждением. Местное предпринимательское сообщество могло бы помочь сфокусировать и определить приоритетность мероприятий путем приведения передовой практики отрасли в соответствие с правовым режимом, а также с помощью государственночастных инициатив. Законодательство в области кибербезопасности может включать следующие компоненты: определение субъектов, имеющих решающее значение для национальной безопасности, со сбалансированными требованиями, предъявляемыми к этим субъектам и их информационным системам; подходы, основанные на управлении рисками для компаний в соответствии с лучшими мировыми практиками, которые учитывают структуру бизнеса и активы; меры по снижению частоты и масштабов кибератак на системы, которые являются ключевыми для экономического роста. В законодательстве о кибербезопасности предусмотрены такие дополнительные положения, как обязанность следить за онлайн-выражением мнений, предварительные проверки аппаратного и/или про- граммного обеспечения, длительные уголовные наказания за нарушения и требования к локализации данных [6]. Важно отметить, что деловые круги на региональном уровне также должны участвовать в процессе разработки стандартов кибербезопасности, чтобы обеспечить удовлетворение своих потребностей.

4) Электронная коммерция лежит в основе большей части цифровой экономики, при этом электронная торговля аналогична традиционному обмену товарами и услугами, но включает в себя цифровые транзакции и соглашения между участниками цепочки поставок. Это указывает на важность регулирования двух областей, имеющих особое значение для электронных транзакций: электронные платежи (e-payment) и электронные подписи (e-signature).

Электронные платежи являются неотъемлемой частью цифровой экономики и получили широкое распространение в последние годы благодаря технологическим инновациям и массовому проникновению мобильных телефонов и смартфонов по всему миру. Существует много типов электронных платежных систем, но в целом их можно разделить на две группы: банковские электронные платежи и небанковские электронные платежи. Банковские электронные платежи включают в себя более традиционные электронные платежи, такие как автоматизированные платежи, кредитные и дебетовые карты, все они связаны с банковскими системами через различные типы банковских счетов. Небанковские электронные платежи, предоставляемые небанковскими посредниками, включают в себя новые, более инновационные методы, такие как PayPal, Alipay и Google Wallet.

Электронные платежи не обходятся без проблем, особенно при работе через границы и финансовые системы. Обе стороны сделки хотят быть уверенными в том, что платежи будут осуществляться без задержек, и органы государственной власти должны позаботиться о том, чтобы сделки защищали тех, кто обладает меньшей рыночной властью. Общие приоритеты как для государственного, так и для частного секторов включают предотвращение мошенничества, а также вопросы безопасности на транзакционном уровне. В зависимости от типа используемой системы электронных платежей существует несколько подходов к регулированию. В целом, банковские электронные платежи жестко регулируются во всем мире с помощью многоуров- 
невой аутентификации транзакций, расследования незаконных транзакций и обеспечение соблюдения банковского законодательства. В отличие от этого, системы регулирования небанковских электронных платежей часто следуют одному из двух подходов: пред-регулирование, когда правовые ограничения особо касаются условий входа на рынок, а при работе на электронном рынке используются только регулятивные меры, и пост-регулирование, когда используются менее ограничительные условия для входа на рынок и в большей степени ограничения ориентированы на обеспечение правил работы на электронном рынке [7].

Помимо электронных платежей, электронные подписи являются важнейшим аспектом транзакций, осуществляемых в цифровой экономике. Традиционные собственноручные подписи являются неотъемлемой частью договорного права; однако с появлением чисто цифровых соглашений концепция электронных подписей создает необычные правовые проблемы. В своей простейшей форме электронная подпись - это компьютерная личная идентификация. За последние несколько десятилетий электронные подписи и связанные с ними проблемы безопасности стали все более сложными, начиная от простых электронных копий собственноручной подписи человека и заканчивая цифровыми подписями, в которых участвуют сторонние поручители.

\section{Заключение}

Таким образом, цифровая экономика стала повсеместным элементом повседневной жизни в большинстве стран. Быстрое распространение информационно-коммуникационной сети Интернет изменило то, как предприятия работают и совершают сделки с потребителями, как граждане получают государственные услуги и как регулирующие органы работают на национальном и международном уровнях. Цифровизация порождает новые бизнес-модели, новые трансграничные цепочки поставок и новые риски. Товары и услуги, продаваемые онлайн, цифровой контент и аналитика данных быстро становятся товарами мировой торговли. Как и сам Интернет, цифровая экономика действительно глобальна: она не имеет границ, и любой пользователь информационно-коммуникационной сети Интернет может немедленно получить доступ к рынкам по всему мира. Это требует особого регулирования защиты прав потребителей и персональных данных в электронном пространстве и обеспечения кибербезопасности электронных транзакций.

\section{Библиографический список}

1. Закон РФ от 07.02.1992 N2300-1 (ред. от 18.07.2019) «О защите прав потребителей».- Режим доступа: http:// www.consultant.ru/document/cons_doc_LAW_305/ (дата обращения 12.03.2020).

2. Кибербезопасность 2019-2020: тенденции и прогнозы.- Режим доступа: https://www.ptsecurity.com/ upload/corporate/ru-ru/analytics/cybersecurity-2019-2020-rus.pdf (дата обращения 12.03.2020).

3. Федеральный закон «О персональных данных» от 27.07.2006 N152-Ф3.- Режим доступа: http://www. consultant.ru/document/cons_doc_LAW_61801/ (дата обращения 12.03.2020).

4. European Commission: Regulation (EU) No. 2017/2394, 27 December 2017.

5. ASEAN, Joint Media Statement of the 48th ASEAN Economic Ministers, August 2016. Web.

6. APEC, Data Privacy Subgroup Meeting with European Union. Web. 2017; Hunton Andrews Kurth, APEC and EU Discuss Interoperability Between Data Transfer Mechanisms. Web. August 25, 2017.

7. Marianne Crowe, Mary Kepler, and Cynthia Merrit, The U.S. Regulatory Landscape for Mobile Payments: Summary Report of Meeting between Mobile Payments Industry Workgroup and Federal and State Regulators on April 24, 2012. Web. July 2012. 